\title{
SOLIDARITY IN THE CLASSROOM. CHARACTERIZING HELPFUL STUDENTS AND SUPPORTIVE RELATIONSHIPS IN THE UNIVERSITY CONTEXT
}

\author{
J.V. Tomás-Miquel, J. Capó Vicedo \\ Universitat Politècnica de València (SPAIN)
}

\begin{abstract}
Helpful students in the university play an important role in the learning process. In addition to disseminating knowledge within the classroom, they are a central element of motivation for those students who need more support. Current research in this topic has especially focused on the students' motivations and attitudes towards solidarity as a general ethical concept. However, despite its importance, less attention has been paid to the specific study of the solidarity inside the classroom. In this research, we especially focus on the personal traits that represent helpful students within the university's classrooms and the role that homophily plays in the establishment of these supportive relationships. On this basis, in this research we try to contribute to this area by answering two main questions: what personal traits, if any, characterize the most helpful students? And, on the other hand, what characteristics, if any, do helpful students share with the students to whom they provide academic support? By addressing a sample of students of the bachelor's degree of Business Administration at Universitat Politècnica de València in Spain and by means of Social Network Analysis techniques, this research provide evidence that most helpful students possess specific personal and behavioural traits. In addition, they also develop preferential supportive behaviours toward certain students with whom they share diverse characteristics. These results may have relevant consequences for the educational community. In this sense the results help lecturers to broaden their knowledge about the behaviour of students at university, allowing a better organisation of working groups and teaching activities.
\end{abstract}

Keywords: Helpful students, University, Academic linkages, Supportive relationships.

\section{INTRODUCTION}

Learning processes of students in university contexts have received preferential attention from the literature over the last few decades. Within this research area, the study of academic collaboration among students has allowed to know its significant influence on learning, academic performance and student satisfaction at university.

Collaboration between students is related to the exchange of knowledge, which in specific contexts such as a class or faculty can lead to the formation and development of instrumental or academic networks. The ties that take place in these networks provide support to the student in the form of sharing notes, jointly solving complex problems and group study, all of which are needed for successful course completion [1]. In this sense, the position of the student in this academic network can be interpreted as an indicator of the extent to which students are engaged in the university $[2,3]$

The empirical evidence existing in the literature has demonstrated an unequal participation of students in these academic networks, both as knowledge providers and recipients. In this knowledge exchange context, more helpful students in a class play a central role in the learning process of the whole classroom. In addition to disseminating knowledge within the classroom, they are a central element of support and motivation for those students who need more help in academic activities.

Solidary attitudes towards other students in the class are driven by a broad internal sense of involvement and responsibility towards others. These behaviours imply being guided by an idea that the actions they develop regularly can have a range of transboundary effects, both present and future, on other people [4].

Current research in this field has especially focused on the students' motivations and attitudes towards solidarity and altruism but as a general ethical concept. In particular, climate change education and education for sustainable development have attracted several contributions over the last few years $[4,5,6]$. However, and despite its importance, less attention has been devoted to the specific study of solidarity among peers. 
In this research, we specifically explore the personal traits that characterize helpful students within the university's classrooms and the role that homophily plays there in the establishment of these supportive relationships among students. Existing literature has attempted to identify the traits of helpful or altruistic people in non-academic contexts and situations [7]. However, university contexts have specific conditions that require a particular study.

Therefore, in this research we try to contribute to this area by exploring two main questions:

- Research Question 1 (RQ1): What personal traits, if any, characterize the most helpful students in the classroom?

- Research Question 2 (RQ2): What characteristics, if any, do helpful students share with the students to whom they provide academic support?

The knowledge about the traits that characterize the most helpful students and with whom they relate may enable lecturers, university managers and policy makers: 1) at a global level, to reflect on the variety of collaborative roles that students can develop in the classroom and, in particular, on the key role in learning that more helpful students can play; 2 ) to identify those students in the classroom who, because of their personal characteristics and attitudes, may be most likely to develop a supportive attitude with other students; and 3) a better organization of working groups and teaching activities in university studies.

In order to answer the above research questions, we conducted an empirical study based on data gleaned from a survey of 47 second-year students of the bachelor's degree of Business Administration at Universitat Politècnica de València in Spain.

This article has been structured as follows. After the introduction, the second section presents the research setting which encompasses the description of the research context and the sample, the data collection procedure and the main variables addressed in the research. The third section describes the results of the empirical study. Finally, main conclusions are reported in the last section, along with the limitations of the work and future research lines.

\section{METHODOLOGY}

\subsection{Research context}

Our sample is composed by students of the bachelor's degree in Business Administration of the Alcoy Campus of the Universitat Politècnica de València in Spain. This bachelor's degree is a four-year fulltime program which requires the completion of 240 ECTS. It aims to train future professionals able to manage, run, advise and assess business organizations.

This research focuses on second-year students because, unlike in the first year, students have already had the opportunity to get to know each other and develop their relationships in depth. On the other hand, the deterioration of relationships due to the passage of time is not excessive, which indicates that it may be an ideal moment to study the situation of the existing academic networks and the phenomenon of solidarity in the classroom. The number of second-year students at this bachelor's degree considered in the sample was 47 , that is, the total number of students in that year at the degree.

Concerning data collection, the information provided by the students of the second-year class during 2016/2017 academic year was the main data source of this research. Before obtaining information from the students, they were informed students about research's objectives and aims, ethical aspects and procedures. The study was carried out using the roster recall method $[8,9,10]$, which involves presenting to the interviewees a full list of the students enrolled in the course who were then asked about their academic relationships with each of them. Specifically, each student was asked about the students he/she had helped to develop projects, exercises and joint classroom activities, as well as to prepare for exams during the second year in the bachelor's degree. This information allowed us to build an academic relationship network. Additionally, students were also asked about different personal and academic aspects of themselves such as age, academic performance and interests, among others. All this information was complemented with secondary data sources such as projects and joint activities developed in different subjects to increase its validity [11]. At the end of the process of data collection, we had 47 valid responses which represents the whole population of second-year students. On this basis, relational data was stored in a $47 \times 47$ matrix, where $x_{i j}=1$ indicates a 
knowledge transfer from student $i$ to student $j$, and $x_{i j}=0$ when there is no knowledge transmission between them.

\subsection{Variables}

The variables used in the research are shown in Table 1.

Table 1. Variables analysed for $R Q 1$ and $R Q 2$

\begin{tabular}{ll}
\hline \hline \multicolumn{1}{c}{ Variable } & Age of the student \\
Age & Gender of the student \\
Gender & Student's occupation during the academic year (only study/additional job) \\
Occupation & Student's average grade at the bachelor's degree after 2 academic years \\
AcademicPerformance & Address of residence during the academic year (family house/independent) \\
Residence & Student's interest in setting up an own business \\
Entrepreneurship & $\begin{array}{l}\text { Type of studies developed before entering university (high school/vocational } \\
\text { training) }\end{array}$ \\
PreviousStudies & $\begin{array}{l}\text { Perception of the student about own extraversion (Likert } 1 . .5 \text { where } 1 \text { is very } \\
\text { introverted and } 5 \text { very extroverted) }\end{array}$ \\
PersonalityTrait_Extraversion & $\begin{array}{l}\text { Perception of the student about own responsibility (Likert 1..5 where 1 is very } \\
\text { little responsible and } 5 \text { very responsible) }\end{array}$ \\
PersonalityTrait_Responsability & $\begin{array}{l}\text { Perception of the student about own kindness (Likert 1..5 where } 1 \text { is very unkind } \\
\text { and 5 very kind) }\end{array}$ \\
PersonalityTrait_Kindness &
\end{tabular}

On the other hand, descriptive data of each of these variables are shown Table 2:

Table 2. Descriptive data of the variables

\begin{tabular}{lll}
\hline \hline \multicolumn{1}{c}{ Variable } & \multicolumn{1}{c}{ Type } & \multicolumn{1}{c}{ Descriptive data } \\
\hline Age & Continuous/ordinal & Average: 22.96 years; Std. deviation: 2.75 \\
Gender & Nominal & Male (23 students); Female (24 students) \\
Occupation & Nominal & Only study (34 students); Study and work (13 students) \\
AcademicPerformance & Continuous/ordinal & Average: 6.70 (range from 0 to 10); Std. deviation: 0.89 \\
Residence & Nominal & Family house (27 students); Independent (20 students) \\
Entrepreneurship & Nominal & Interested (20 students); Not interested (27 students) \\
PreviousStudies & Nominal & High school (34); Vocational training (13) \\
PersonalityTrait_Extraversion & Continuous/ordinal & Average: 3.47 (range from 1 to 5); St. deviation: 0.78 \\
PersonalityTrait_Responsability & Continuous/ordinal & Average: 4.04 (range from 1 to 5); St. deviation: 0.86 \\
PersonalityTrait_Kindness & Continuous/ordinal & Average: 3.96 (range from 1 to 5); St. deviation: 0.88 \\
\hline \hline
\end{tabular}

\section{RESULTS}

Before addressing research questions, Table 3 presents the main characteristics of the academic network under study estimated through UCINET Software [12].

Table 3. Descriptive statistics of the academic network

\begin{tabular}{cccccc}
\hline \hline Nodes (students) & Ties & Average degree & Density & Isolated nodes & Gini index \\
\hline 47 & 343 & 7.298 & 0.159 & 0 & 0.405 \\
\hline \hline
\end{tabular}

As can be observed, students analysed considerably develop academic relationships at the university with a network density of $15.9 \%$, an average degree of 7.298 and no isolated students. This finding is 
in line with previous evidence which also analysed academic linkages between university students [10].

In addition, the Gini index is intended to explain whether there are some students that develop more relationships than others. It ranges from 0 to 1 where 0 means that there is a complete homogeneity in the number of links established per student in the class and 1 the opposite. The results show a certain homogeneity in the number of links established by students which is, to a certain extent, consistent with second year students, because, as time passes, students can get to know each other better and develop more relationships, especially those less connected to the academic network in their first year at the university.

Finally, Fig. 1 presents the graphical representation of the network analysed. An arrow from $i$ to $j$ in the figures represents a transmission of knowledge from $i$ to $j$. The bigger the size of the node, the more connected it is to the network.

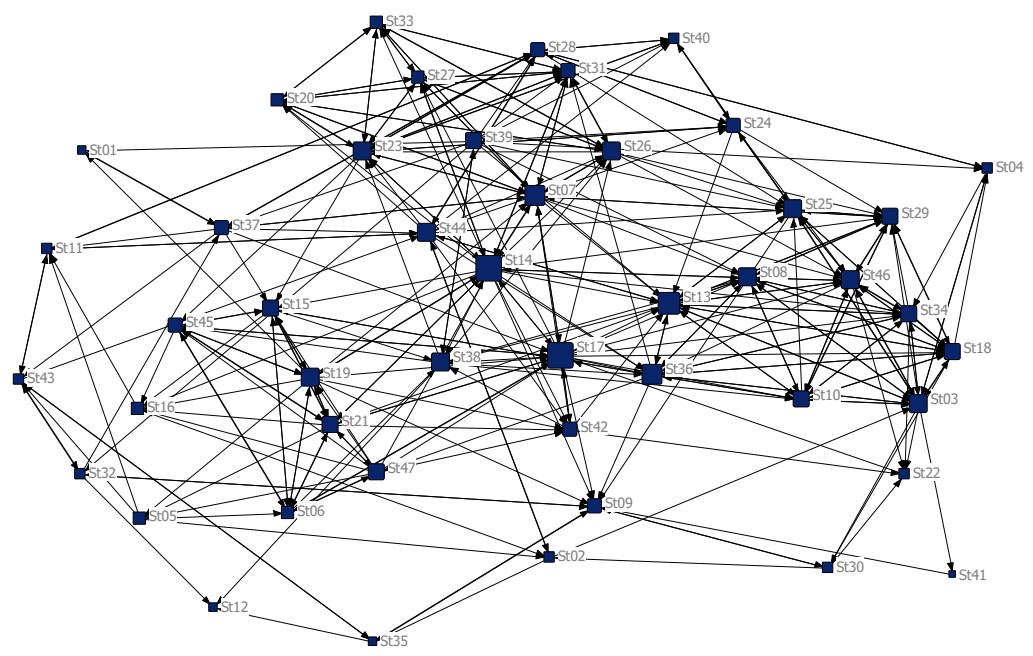

Figure 1. Representation of the academic network analysed

\subsection{Results for Research Question 1}

RQ1 aims to explore the personal traits that characterize most helpful students. In order to proceed, the students analysed in the sample were classified in three equal groups according to their level of support to other students. In particular, the students were classified according to their outdegree in the academic network, that is, the number of links established with other students to give them support.

Because the sample size is not a multiple of three, a first group of 16 students (less supportive students), a second group of 16 students (intermediate supportive students) and a last group of 15 students (more supportive students) were established.

Once the three groups were defined, the differences between the different groups in the variables shown in Table 1 were studied.

Since the assumptions of normality could not be met, non-parametric tests were used to analyse the research questions.

On the other hand, given that the variables to be studied present different characteristics, the nonparametric statistical tests were adapted to each one of them. In particular, for nominal variables such as Gender, Occupation, Residence, Entrepreneurship and PreviousStudies, the Chi-Square test was used. On the other hand, for the continuous and ordinal variables, the Kruskal-Wallis and Bonferroni-Dunn post-hoc tests were applied.

The results of the chi-square test are shown in Table 4. 
Table 4. Chi-square tests statistics for analysis involving nominal variables in RQ1

\begin{tabular}{|c|c|c|c|c|c|}
\hline Variable & $\begin{array}{c}L^{L H S^{b}} \\
34.043 \% \\
(n=16)\end{array}$ & $\begin{array}{c}I H S^{c} \\
34.043 \% \\
(n=16)\end{array}$ & $\begin{array}{c}M^{M} S^{d} \\
31.915 \% \\
(n=15)\end{array}$ & Chi-square $^{a}$ & Cramer's V \\
\hline Gender & & & & $8.899^{* *}$ & 0.435 \\
\hline Male & $3(13.04 \%)$ & $10(43.48 \%)$ & $10(43.48 \%)$ & & \\
\hline Female & $13(54.17 \%)$ & $6(25 \%)$ & $5(20.83 \%)$ & & \\
\hline Occupation & & & & 0.979 & 0.144 \\
\hline Only study & $13(38.24 \%)$ & $11(32.35 \%)$ & $10(29.41 \%)$ & & \\
\hline Study and work & $3(23.08 \%)$ & $5(38.46 \%)$ & $5(38.46 \%)$ & & \\
\hline Residence & & & & $8.240^{* *}$ & 0.419 \\
\hline Family house & $5(18.52 \%)$ & $13(48.15 \%)$ & $9(33.33 \%)$ & & \\
\hline Independent & $11(55 \%)$ & $3(15 \%)$ & $6(30 \%)$ & & \\
\hline Entrepreneurship & & & & $7.286^{* *}$ & 0.394 \\
\hline Interested & $3(15 \%)$ & $7(35 \%)$ & $10(50 \%)$ & & \\
\hline Not interested & $13(48.15 \%)$ & $9(33.33 \%)$ & $5(18.52 \%)$ & & \\
\hline PreviousStudies & & & & 0.979 & 0.144 \\
\hline High School & $11(32.35 \%)$ & $13(38.24 \%)$ & $10(29.41 \%)$ & & \\
\hline Vocational training & $5(38.46 \%)$ & $3(23.08 \%)$ & $5(38.46 \%)$ & & \\
\hline
\end{tabular}

a Significant at 0.1 level $\left({ }^{*}\right)$; Significant at 0.05 level $\left({ }^{* *}\right)$; Significant at 0.01 level $\left({ }^{* * *}\right)$

${ }^{\mathrm{b}}$ LHS $=$ Less Helpful Students; ${ }^{\mathrm{c}} \mathrm{HS}=$ Intermediate Helpful Students; ${ }^{\mathrm{d}}$ MHS = More Helpful Students

As can be verified in the table, the data meet the minimum required conditions to apply the Chi-square test, since at least $80 \%$ of the cells in each of the five variable analyses present five or more cases.

Concerning the analyses, the variables Gender, Residence and Entrepreneurship present significant results. Therefore, we found significant differences of these three traits in the students according to the intensity in which they provide academic support to others. Specifically, we found that the students who provide the most support to the rest of the students in the classroom are predominantly those of the male gender, those who live in the family home, and those who are most interested in entrepreneurial activities.

On the other hand, the results after applying Kruskal-Wallis and Bonferroni-Dunn post-hoc tests statistics for the ordinal and continuous variables are shown in Table 5.

Table 5. Kruskal-Wallis and Bonferroni-Dunn post-hoc tests statistics for analysis involving continuous variables in RQ1

\begin{tabular}{|c|c|c|c|c|c|c|c|}
\hline \multirow{2}{*}{ Variable } & \multirow{2}{*}{$\begin{array}{c}\text { Chi- } \\
\text { square }^{a}\end{array}$} & \multirow{2}{*}{$\begin{array}{c}L^{L} S^{b} \\
\text { mean } \\
\text { rank }\end{array}$} & \multirow{2}{*}{$\begin{array}{c}I H S^{c} \\
\text { mean } \\
\text { rank }\end{array}$} & \multirow{2}{*}{$\begin{array}{c}M H S^{d} \\
\text { mean } \\
\text { rank }\end{array}$} & \multicolumn{3}{|c|}{ Pair-wise comparisons ${ }^{a e}$} \\
\hline & & & & & LHS-IHS & LHS-MHS & IHS-MHS \\
\hline Age & $8.241^{* *}$ & 31.81 & 19.34 & 20.63 & $\begin{array}{c}12.469^{* *} \\
(4.759)\end{array}$ & $\begin{array}{l}11.179^{*} \\
(4.838)\end{array}$ & $\begin{array}{l}-1.290 \\
(4.838)\end{array}$ \\
\hline AcademicPerformance & 3.722 & 25.22 & 27.69 & 18.77 & & & \\
\hline PersonalityTrait_Extraversion & 2.053 & 22.81 & 21.62 & 27.80 & & & \\
\hline PersonalityTrait_Responsability & $8.832^{* *}$ & 31 & 23.09 & 17.50 & $\begin{array}{c}7.906 \\
(4.500)\end{array}$ & $\begin{array}{c}13.500^{* * *} \\
(4.575)\end{array}$ & $\begin{array}{c}5.594 \\
(4.575)\end{array}$ \\
\hline PersonalityTrait_Kindness & $18.176^{\star * *}$ & 13.19 & 27.88 & 31.40 & $\begin{array}{c}-14.688^{* * *} \\
(4.491)\end{array}$ & $\begin{array}{c}-18.212^{* * *} \\
(4.565)\end{array}$ & $\begin{array}{l}-3.525 \\
(4.565)\end{array}$ \\
\hline Sample size & & 16 & 16 & 15 & & & \\
\hline
\end{tabular}

a Significant at 0.1 level $\left({ }^{*}\right)$; Significant at 0.05 level $\left(^{* *}\right)$; Significant at 0.01 level $\left(^{* * *}\right)$

${ }^{\mathrm{b}}$ LHS = Less Helpful Students; ${ }^{\mathrm{c}} \mathrm{IHS}=$ Intermediate Helpful Students; ${ }^{\mathrm{d}} \mathrm{MHS}=$ More Helpful Students

e Top values are mean differences between groups and bottom values are standard errors 
The results also reveal a significant influence of the variables Age, PersonalityTrait_Responsability and PersonalityTrait_Kindness on the level of academic support to other students. In particular, younger, less responsible and kinder students have higher levels of support for other students.

\subsection{Results for Research Question 2}

Regarding RQ2, it aims to investigate the main characteristics that helpful students share with the students to whom they provide academic support.

To proceed and by means of the UCINET application [12], we analysed the level of homophily of every actor in the network. In particular, we calculated for each student and variable, the number of ties between ego and an alter in the same attribute category divided by ego's total number of ties, that is, the percentage of ties of each student with students in the same attribute category.

To homogenize the analysis, the continuous variables were discretized, according to three groups for the Age and AcademicPerformance variables and according to two groups for the PersonalityTrait_Extraversion, PersonalityTrait_Responsability and PersonalityTrait_Kindness variables.

The results obtained for the group of the 15 most helpful students are shown in Table 6 .

Table 6. For most helpful students, percentage of support linkages with students with the same or similar value in each characteristic analysed

\begin{tabular}{|c|c|c|c|c|c|c|c|c|c|c|}
\hline Variable & ঠे & 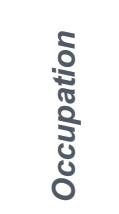 & 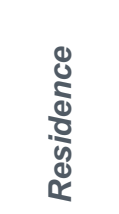 & 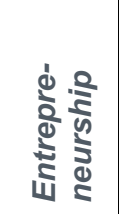 & 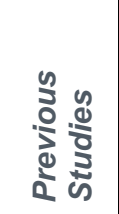 & ळ & 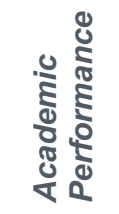 & 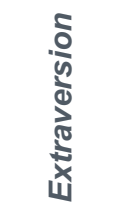 & 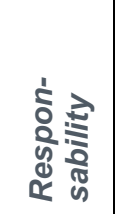 & 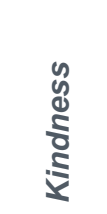 \\
\hline Student03(St03) & $76.92 \%$ & $61.54 \%$ & $15.38 \%$ & $61.54 \%$ & $76.92 \%$ & $76.92 \%$ & $92.31 \%$ & $46.15 \%$ & $15.38 \%$ & $69.23 \%$ \\
\hline Student07(St07) & $38.46 \%$ & $92.31 \%$ & $76.92 \%$ & $61.54 \%$ & $84.62 \%$ & $100 \%$ & $23.08 \%$ & $61.54 \%$ & $15.38 \%$ & $100 \%$ \\
\hline Student08(St08) & $88.89 \%$ & $66.67 \%$ & $88.89 \%$ & $22.22 \%$ & $66.67 \%$ & $77.78 \%$ & $88.89 \%$ & $44.44 \%$ & $11.11 \%$ & $100 \%$ \\
\hline Student13(St13) & $90.91 \%$ & $54.55 \%$ & $81.82 \%$ & $72.73 \%$ & $27.27 \%$ & $72.73 \%$ & $100 \%$ & $27.27 \%$ & $63.64 \%$ & $90.91 \%$ \\
\hline Student14(St14) & $50 \%$ & $75 \%$ & $65 \%$ & $35 \%$ & $70 \%$ & $75 \%$ & $20 \%$ & $55 \%$ & $75 \%$ & $85 \%$ \\
\hline Student17(St17) & $41.18 \%$ & $76.47 \%$ & $17.65 \%$ & $52.94 \%$ & $70.59 \%$ & $76.47 \%$ & $70.59 \%$ & $52.94 \%$ & $23.53 \%$ & $82.35 \%$ \\
\hline Student18(St18) & $90 \%$ & $70 \%$ & $80 \%$ & $60 \%$ & $80 \%$ & $90 \%$ & $90 \%$ & $50 \%$ & $70 \%$ & $70 \%$ \\
\hline Student19(St19) & $83.33 \%$ & $16.67 \%$ & $50 \%$ & $25 \%$ & $75 \%$ & $66.67 \%$ & $75 \%$ & $66.67 \%$ & $25 \%$ & $58.33 \%$ \\
\hline Student21(St21) & $72.73 \%$ & $18.18 \%$ & $45.45 \%$ & $72.73 \%$ & $27.27 \%$ & $72.73 \%$ & $81.82 \%$ & $72.73 \%$ & $63.64 \%$ & $72.73 \%$ \\
\hline Student23(St23) & $54.55 \%$ & $81.82 \%$ & $18.18 \%$ & $36.36 \%$ & $9.09 \%$ & $100 \%$ & $27.27 \%$ & $36.36 \%$ & $90.91 \%$ & $90.91 \%$ \\
\hline Student36(St36) & $80 \%$ & $20 \%$ & $90 \%$ & $50 \%$ & $30 \%$ & $20 \%$ & $90 \%$ & $60 \%$ & $70 \%$ & $90 \%$ \\
\hline Student39(St39) & $58.33 \%$ & $25 \%$ & $66.67 \%$ & $66.67 \%$ & $66.67 \%$ & $83.33 \%$ & $33.33 \%$ & $33.33 \%$ & $75 \%$ & $75 \%$ \\
\hline Student44(St44) & $75 \%$ & $33.33 \%$ & $58.33 \%$ & $50 \%$ & $50 \%$ & $75 \%$ & $58.33 \%$ & $58.33 \%$ & $83.33 \%$ & $83.33 \%$ \\
\hline Student46(St46) & $90 \%$ & $50 \%$ & $90 \%$ & $70 \%$ & $70 \%$ & $70 \%$ & $100 \%$ & $50 \%$ & $70 \%$ & $80 \%$ \\
\hline Student47(St47) & $10 \%$ & $70 \%$ & $40 \%$ & $80 \%$ & $20 \%$ & $10 \%$ & $80 \%$ & $70 \%$ & $30 \%$ & $70 \%$ \\
\hline Average & $66.69 \%$ & $54.10 \%$ & $58.95 \%$ & $54.45 \%$ & $54.94 \%$ & $71.11 \%$ & $68.71 \%$ & $52.32 \%$ & $52.13 \%$ & $81.19 \%$ \\
\hline Std. deviation & 0.24 & 0.25 & 0.27 & 0.18 & 0.25 & 0.25 & 0.29 & 0.13 & 0.28 & 0.12 \\
\hline
\end{tabular}

Although with obvious caution due to the existence of a very limited set of records, the values of the percentages obtained from the variables gender, age, academic performance and Kindness are far from a random distribution of the data. Therefore, based on these evidences we can apparently conclude that the most helpful students in the sample prefer students of the same sex and with similar ages, academic performance and kindness traits.

On the other hand, it is also interesting to know if this behaviour is exclusive to most helpful students, or if, on the other hand, it is a general behaviour of the students analysed independently of their level of support to other students.

To proceed, we applied the nonparametric Kruskal-Wallis and Bonferroni-Dunn post-hoc tests to explore the differences between groups. Table 7 presents the results of these tests. 
Table 7. Kruskal-Wallis and Bonferroni-Dunn post-hoc tests statistics for analysis involving significant homophily variables in RQ2

\begin{tabular}{|c|c|c|c|c|c|c|c|}
\hline \multirow{2}{*}{ Variable } & \multirow{2}{*}{ Chi-square $^{a}$} & \multirow{2}{*}{$\begin{array}{l}L H S^{b} \\
\text { mean } \\
\text { rank }\end{array}$} & \multirow{2}{*}{$\begin{array}{c}I^{\prime H S^{c}} \\
\text { mean } \\
\text { rank }\end{array}$} & \multirow{2}{*}{$\begin{array}{l}\text { MHS } \\
\text { mean } \\
\text { rank }\end{array}$} & \multicolumn{3}{|c|}{ Pair-wise comparisons ${ }^{a e}$} \\
\hline & & & & & LHS-IHS & LHS-MHS & IHS-MHS \\
\hline Homophily_Gender & 0.586 & 25.63 & 22.16 & 22.80 & & & \\
\hline Homophily_Age & $15.365^{\star * *}$ & 12.77 & 30.97 & 26.27 & $\begin{array}{l}-18.202^{* *} \\
(4.795)\end{array}$ & $\begin{array}{c}-13.500^{* *} \\
(4.872)\end{array}$ & $\begin{array}{c}4.702 \\
(4.795)\end{array}$ \\
\hline $\begin{array}{l}\text { Homophily_AcademicPerformanc } \\
\text { e }\end{array}$ & 1.282 & 26.60 & 22.47 & 21.50 & & & \\
\hline Homophily_Kindness & $11.381^{* * *}$ & 14.07 & 29.31 & 26.73 & $\begin{array}{c}-15.246^{* * *} \\
(4.803)\end{array}$ & $\begin{array}{c}-12.667^{\star *} \\
(4.879)\end{array}$ & $\begin{array}{c}2.579 \\
(4.803)\end{array}$ \\
\hline Sample size & & 16 & 16 & 15 & & & \\
\hline
\end{tabular}

a Significant at 0.1 level $\left({ }^{\star}\right)$; Significant at 0.05 level $\left(^{* *}\right)$; Significant at 0.01 level $\left({ }^{* * *}\right)$

${ }^{\mathrm{b}}$ LHS = Less Helpful Students; ${ }^{\mathrm{c}} \mathrm{IHS}=$ Intermediate Helpful Students; ${ }^{\mathrm{d}} \mathrm{MHS}=$ More Helpful Students

e Top values are mean differences between groups and bottom values are standard errors

The results show differences between groups for the Age and Kindness variables. Thus, based on them, the levels of homophily in age, i.e., the preference for supporting students of the same age, is greater in intermediate and more helpful students than in less helpful students. In other words, intermediate and more helpful students are more prone to establish support relationships with students of the same age than less helpful students.

In the same way, the levels of homophily in kindness traits are also higher in intermediate and more helpful students than in less helpful students. In particular, the former have a greater tendency to establish support links with students with the same levels of kindness than the less helpful students.

\section{CONCLUSIONS}

This research has explored the traits that characterize the most helpful students in university classrooms, as well as those traits that they share with the students they help. The results obtained are, in our opinion, relevant since they have allowed us to confirm that the most helpful students effectively present characteristics that are different from the rest. We have statistically contrasted this research question on different personal, performance, attitude and behaviour variables. The results have revealed that the variables in which the most helpful students have shown particular characteristics are gender, age, place of residence, entrepreneurial attitude and personality traits of responsibility and kindness.

While certain results of the study may require more in-depth analysis in order to be generalizable as they may depend specifically on the context of study, such as the fact that male students predominate in the group of the more helpful students, other results may be relevant. In this sense, the results reveal that younger students are more prone than the rest to support other students. This can be explained by the fact that older students may have less time available to give support because they also work or live independently in their own home or because their greater social experience both at and outside the university makes them more reserved and distrustful. In addition, another notable result is that students living in family homes are more likely to provide support than those living independently in their own home. This can also be justified by the fact that those living in family homes generally have more time to give support, since they generally do not have to take complete care of their home. On the other hand, the results also offer another interesting outcome, which is that students more interested in entrepreneurship are likely to offer more help to peers than those who are not. The explanation of these results can be associated with the qualities generally possessed by people with high entrepreneurial attitudes. Thus, studies on entrepreneurship have shown that these people require communication and collaboration skills different from the rest, understanding these elements as key processes for achieving their objectives $[13,14,15]$. Finally, the research has allowed us to know two personality traits that characterize the most helpful students, namely their low levels of responsibility and high levels of kindness. While the explanation of the high levels of kindness of the more helpful students may become obvious, the interpretation of their limited levels of responsibility may be somewhat a bit more complex. In this sense, responsibility can be understood as the quality of people who stand out for being aware of their obligations, acting in accordance with them. Therefore, 
the rigorous fulfilment of personal and academic obligations developed by university students rich in this quality can prevent them from supporting other students, given that this task is altruistic and not mandatory.

Complementary to this, the study has also allowed us to understand the personal preferences of the most helpful students when it comes to providing support. In this sense, the study reveals the preference of more helpful students to provide support to similar students in traits such as age, gender, academic performance and kindness. Finally, the study also discloses that homophily levels in relation to age and kindness are higher in intermediate and more helpful students than in less helpful students.

We consider that the results of this research open the door to an understanding of the traits that characterize supportive students in the classroom, as well as the personal, attitudinal, and academic traits they share with the students they help. In addition, we believe that our analysis may suggest important implications for policy and strategy. Our findings might help guide universities on the development of strategies aimed at improving the management of work groups both at a general level in the university and at the level of the classroom itself, and pave the way and encourage researchers to the development of new studies that delve into these aspects.

Finally, this study suffers from certain limitations. In this sense, and as previously commented, the research has focused on a specific course and a specific bachelor's degree from a Spanish university, which, although it has facilitated its analysis by focusing on a specific context, makes it very difficult to generalize the results to other university studies or contexts. Therefore, new analyses in different classrooms and universities are required to study how other cases vary. On the other hand, this crosssectional study has made it possible to obtain interesting and comprehensive results. However, an analysis of the dynamics of academic networks throughout the different courses in which a student is in the university by means of techniques such as stochastic actor-oriented models would additionally allow us to explore how the helpful behaviour of university students evolves over time, as well as the factors that enhance or undermine it. For example, if being in contact with helpful students, strengthens this behaviour in students who lack it. Nevertheless, we leave these studies for future new research.

\section{REFERENCES}

[1] B. Chen, F. Wang, and J. Song, "Are they connected? Exploring academic and social networks among MPA students at a Chinese University", Journal of Public Affairs Education, vol. 18, no. 1, pp. 137-156, 2012.

[2] S. L. Thomas, "Ties that bind: A social network approach to understanding student integration and persistence", Journal of Higher Education, vol. 71, no. 5, pp. 591-615, 2000.

[3] K. L. Krause, and H. Coates, "Students' engagement in first-year university", Assessment \& Evaluation in Higher Education, vol. 33, no. 5, pp. 493-505, 2008.

[4] T. Torbjörnsson, T. and L. Molin, "Who is solidary? A study of Swedish students' attitudes towards solidarity as an aspect of sustainable development", International Research in Geographical and Environmental Education, vol. 23, no. 3, pp. 259-277, 2014.

[5] T. Torbjörnsson, and L. Molin, "In school we have not time for the future: voices of Swedish upper secondary school students about solidarity and the future", International Research in Geographical and Environmental Education, vol. 24, no. 4, pp. 338-354, 2015.

[6] M. Ojala, "Hope in the face of climate change: Associations with environmental engagement and student perceptions of teachers' emotion communication style and future orientation", The Journal of Environmental Education, vol. 46, no. 3, pp. 133-148, 2015.

[7] D. Tait, Personality Traits of Altruistic People: Empathy and the Big Five Factors, Dissertation Thesis, 2009.

[8] E. Giuliani, and M. Bell, "The micro-determinants of meso-level learning and innovation: evidence from a Chilean wine cluster", Research policy, vol. 34, no. 1, pp. 47-68, 2005.

[9] A. Morrison, and R. Rabellotti, "Knowledge and information networks in an Italian wine cluster", European Planning Studies, vol. 17, no. 7, pp. 983-1006, 2009. 
[10] J. V. Tomás-Miquel, M. Expósito-Langa, and D. Nicolau-Juliá, "The influence of relationship networks on academic performance in higher education: a comparative study between students of a creative and a non-creative discipline", Higher Education, vol. 71, no. 3, pp. 307-322, 2016.

[11] R. K. Yin, Case study research, design and methods. Beverly Hills: Sage, 1989.

[12] S. P. Borgatti, M. G. Everett, and L. C. Freeman, Ucinet 6 for Windows: Software for Social Network Analysis. Harvard, MA: Analytic Technologies, 2002.

[13] V. Pollard, and E. Wilson, "The "Entrepreneurial Mindset" in creative and performing arts higher education in Australia", Artivate: A Journal of Entrepreneurship in the Arts, vol. 3, no. 1, pp. 3-22, 2014.

[14] D. Welsh, and M. Dragusin, "Entrepreneurship education in higher education institutions as a requirement in building excellence in business: The case of the University of North Carolina at Greensboro", Forum Ware International, vol. 1, pp. 266-272, 2011.

[15] J. P. Warhuus, L. Tanggaard, S. Robinson, and S. M. Ernø, "From I to We: collaboration in entrepreneurship education and learning?", Education + Training, vol. 59, no. 3, pp. 234-249, 2017. 